\title{
Measuring diffuse metabolic activity on FDG-PET/CT: new method for evaluating Langerhans cell histiocytosis activity in pulmonary parenchyma ${ }^{\text {is }}$
}

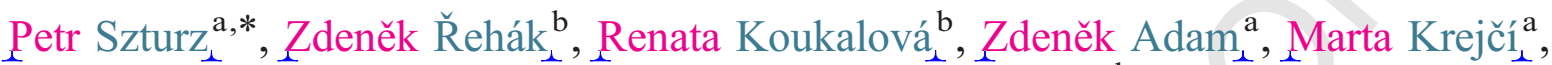

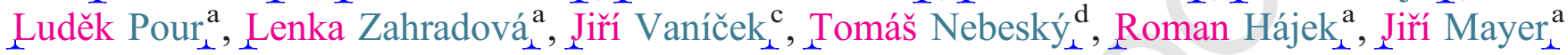 \\ ${ }^{a}$ Department of Internal Medicine-Hematooncology, Faculty of Medicine of Masaryk University and University Hospital Brno, Czech Republic \\ ${ }^{\mathrm{b}}$ Department of Nuclear Medicine, PET Centre at the Masaryk Memorial Cancer Institute, Brno, Czech Republic \\ ${ }^{\mathrm{c}}$ Department of Imaging Methods, Faculty of Medicine of Masaryk University and St. Anne's University Hospital Brno, Czech Republic \\ ${ }^{\mathrm{d}}$ Radiological Clinic, Faculty of Medicine of Masaryk University and University Hospital Brno, Czech Republic \\ Received 6 June 2011; received in revised form 23 August 2011; accepted 4 October 2011
}

\section{Abstract}

Introduction: Pulmonary Langerhans cell histiocytosis (PLCH) is a rare cause of interstitial lung disease characterized by formation of nodules in the active phase of the disease that evolve into nonactive cystic lesions later on. To evaluate PLCH activity in patients, we developed a new method for measuring diffuse metabolic activity on fluorine-18-fluorodeoxyglucose positron emission tomography/ computed tomography (FDG-PET/CT) using a lung-to-liver activity ratio.

Material and Methods: We retrospectively studied a series of 4 FDG-PET and 23 FDG-PET/CT scans from 7 patients with PLCH and analyzed a sample of 100 randomly chosen FDG-PET/CT studies free from any known lung or hepatic diseases. Maximum standardized uptake value (SUVmax) in a spherical volume $(6-8 \mathrm{~cm}$ in diameter) in the right lung was put into relation with SUVmax in a spherical volume (9-10 cm in diameter) in the reference liver parenchyma to set up the SUVmaxPULMO/SUVmaxHEPAR index. The index values were compared to the disease course in each patient.

Results: In patients with PLCH, a close correlation between the index value and the disease course was found in all seven subjects, where the increasing index values indicated disease activity, while decreasing index values were observed after therapy administration. In the group of 100 healthy control subjects, we found index values lower than 0.3 in $80 \%$ and lower than 0.4 in $96 \%$ [range: $0.14-0.43 ; 0.24 \pm 0.07$ (100)]. Conclusion: Measuring SUVmaxPULMO/SUVmaxHEPAR values and their time-trend monitoring represent simple, noninvasive screening tools allowing an early diagnosis and treatment response follow-up assessment in patients with PLCH.

(C) 2011 Published by Elsevier Inc.

Keywords: Langerhans cell histiocytosis; Interstitial lung disease; Positron emission tomography; Pulmonary function tests; High-resolution computed tomography (HRCT)

\section{Introduction}

Pulmonary Langerhans cell histiocytosis $(\mathrm{PLCH})$ is a rare condition, the symptoms of which are nonspecific and

\footnotetext{
Conflict of interest: The authors declare that they have no conflict of interest.

* Corresponding author. Department of Internal Medicine-Hematooncology, University Hospital Brno, Jihlavská 20, 62500 Brno, Czech Republic. Tel.: +42 0532233064; fax: +420532233603

E-mail address: petr.szturz@fnbrno.cz (P. Szturz).
}

include cough, chest pains and dyspnea, and sometimes, 34 even pneumothorax may be its first manifestation. In the 35 early stages of the disease, small nodules evolving through 36 cavitated forms into thick-walled, later thin-walled and 37 eventually confluent cysts, and start to build up in pulmonary 38 parenchyma. These changes predominantly affect upper lung 39 zones with relative sparing of the lung bases [1]. Radiolog- 40 ical appearance of advanced PLCH on conventional 41 radiographs or even high-resolution computed tomography 42 (HRCT) scans may be difficult to distinguish from 43 emphysema, which often leads to delays in getting the 44 
right diagnosis and initiating proper treatment. In addition, $\mathrm{X}$-ray findings are sometimes inconclusive without any correlation to serious clinical symptoms (Fig. 1).

Langerhans cell histiocytosis limited only to pulmonary parenchyma is a smoke-related interstitial lung disease referred to as isolated $\mathrm{PLCH}$, and it has a better prognosis than Langerhans cell histiocytosis with multisystemic involvement including lungs. Although having different prognoses and therapeutic approaches, these two entities present the same clinical, radiological and histopathological manifestations $[2,3]$. PLCH is responsible for $3 \%-5.5 \%$ of interstitial lung diseases [4-6]. Larger epidemiologic data are available from Japan [7], where the estimated crude prevalences in males and females are 0.27 and 0.07 per 100,000 population, respectively. Most patients with PLCH are young cigarette smokers between 20 and 40 years of age [1].

Diagnostics include surgical lung biopsy and bronchoalveolar lavage with $\mathrm{CD} 1 \mathrm{a}+$ elements (Langerhans cells) analysis [8]. Additionally, in the setting of multisystemic Langerhans cell histiocytosis, characteristic HRCT scan findings in the lungs may be sufficient for the diagnosis. Treatment is indicated in patients with multisystem involvement or when a progression of pulmonary lesions has been confirmed. The progression is characterized by increasing 69 numbers of nodules, whereas formation and enlargement of 70 cysts are only a natural disease development into its terminal, 71 end-stage phase. HRCT scans and pulmonary function tests 72 are routinely applied in the follow-up; however, determining 73 the number of nodules on HRCT scans is extremely difficult 74 and time consuming, and pulmonary function tests cannot 75 always distinguish between end-stage cystic disease and 76 active PLCH [6,9].

To facilitate the PLCH activity assessment, we developed 78 and verified a new method for measuring diffuse metabolic 79 activity on fluorine-18-fluorodeoxyglucose (FDG) positron 80 emission tomography/computed tomography (PET/CT) scan 81 imaging using the SUVmaxPULMO/SUVmaxHEPAR 82 index. In this paper, we describe this methodology and 83 verify its validity on a retrospective study of a PLCH 84 patient cohort.

\section{Materials and methods}

\subsection{Patients}

During a 21-year period from November 1, 1989, to 88 January 1, 2011, 23 patients were diagnosed with Langerhans 89

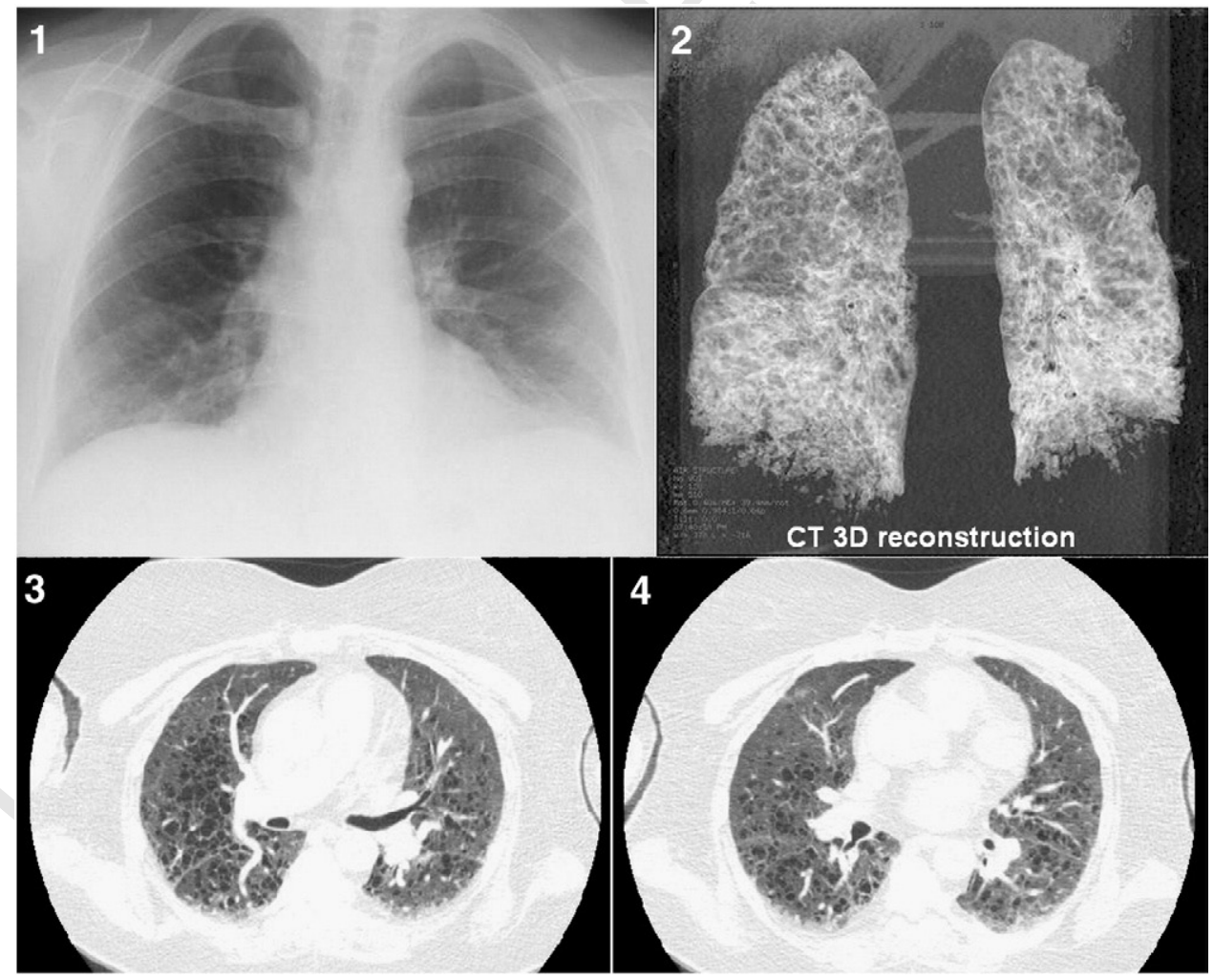

Fig. 1. Different radiological imaging modalities of the chest in a patient with multisystemic Langerhans cell histiocytosis with pulmonary involvement (female, born 1955). The patient presenting with fevers and dyspnea was admitted to hospital with suspected pneumonia in July 2010 . There were no abnormalities seen on conventional radiography (1), in contrast to HRCT imaging ( 3 and 4) showing apart from hypostatic pneumonia also diffuse small cysts (4-15 mm in size) in both lung fields resembling emphysema, which was visualized using 3D reconstruction (2). Cystic lung disease, complicated by bacterial infection, was an accidental finding in this patient. However, retrospective analysis of the SUVmaxPULMO/SUVmaxHEPAR index in preceding four PET examinations (20042010) shows a high probability of a previous history of PLCH (Table 2). 
cell histiocytosis and followed up at our department. Out of them, 15 patients had either single-systemic (nine patients) or multisystemic (six patients) disease without pulmonary involvement. The remaining eight patients were diagnosed with PLCH, of whom seven underwent FDG-PET scan imaging. In total, 4 FDG-PET and 23 FDG-PET/CT studies were performed between the years 2004 and 2010. The study follow-up period started with the first FDG-PET examination in March 2004.

The indications for FDG-PET or FDG-PET/CT scanning included: (a) searching for multiorgan involvement of an extrapulmonary (verified by bone, lymph node or skin biopsies) Langerhans cell histiocytosis (four scans) as well as (b) of known PLCH (two scans), (c) differential diagnosis of pituitary stalk infiltration (one scan) and (d) follow-up of patients (20 scans). The patients were free from any other active lung or liver disease at the time of PET scanning. The diagnosis of PLCH was based on pathological examinations (three patients) or pathognomonic HRCT scan findings (four patients). Patients who did not agree to the use of their medical records for research were not included in this study.

\subsection{FDG-PET/CT scan imaging}

In the PLCH patient cohort, we performed FDG-PET and FDG-PET/CT scanning in euglycemia after fasting for $6 \mathrm{~h}$. FDG-PET scan images of the body, at the extent from the proximal thirds of femurs to the cranial base (with included the head in four scans), were obtained $60 \mathrm{~min}$ after 116 intravenous injection of fluorodeoxyglucose (range of 117 applied activity: 312-409 MBq). Until 2008, data acquisi- 118 tion was performed on a PET scanner (ECAT ACCEL 119 SIEMENS) in a three-dimensional (3D) mode and, later, 120 from 2008, on a hybrid PET/CT scanner (True Point PET-CT 121 Biograph 64 SIEMENS). Emission and transmission scans 122 were reconstructed by using an iterative reconstruction 123 algorithm. On acquired data, attenuation correction was 124 applied. Due to repeated follow-up FDG-PET/CT scanning, 125 in most studies, low-dose CT protocol reducing radiation 126 load significantly was used. With the remaining studies, 127 high-dose CT mode was applied. The scan field of view was 128 50 or $70 \mathrm{~cm}$ according to a patient's body habitus. The 129 acquisition parameters for CT were as follows: slice $5 \mathrm{~mm}, 130$ collimation $24 \times 1.2 \mathrm{~mm}$, pitch $0.8 \mathrm{~mm}$. To optimize lung 131 parenchyma imaging, the following reconstruction algorithm 132 was used: slice 1.5-2.0 mm, kernel B $80 \mathrm{f}$ (ultra sharp), 133 reconstruction increment $0.4 \mathrm{~mm}$, window-lung. Maximum 134 standardized uptake values (SUVmax) were measured for 135 semiquantitative analysis.

\subsection{SUVmaxPULMO/SUVmaxHEPAR index}

137

Nodules in PLCH often measure several millimeters (4-6 138 $\mathrm{mm}$ ) and are below detectable levels of used PET scanners 139 (about $7 \mathrm{~mm}$ ), which precludes direct measurement of their 140 activity. Therefore, we tried to find these active lesions in a 141

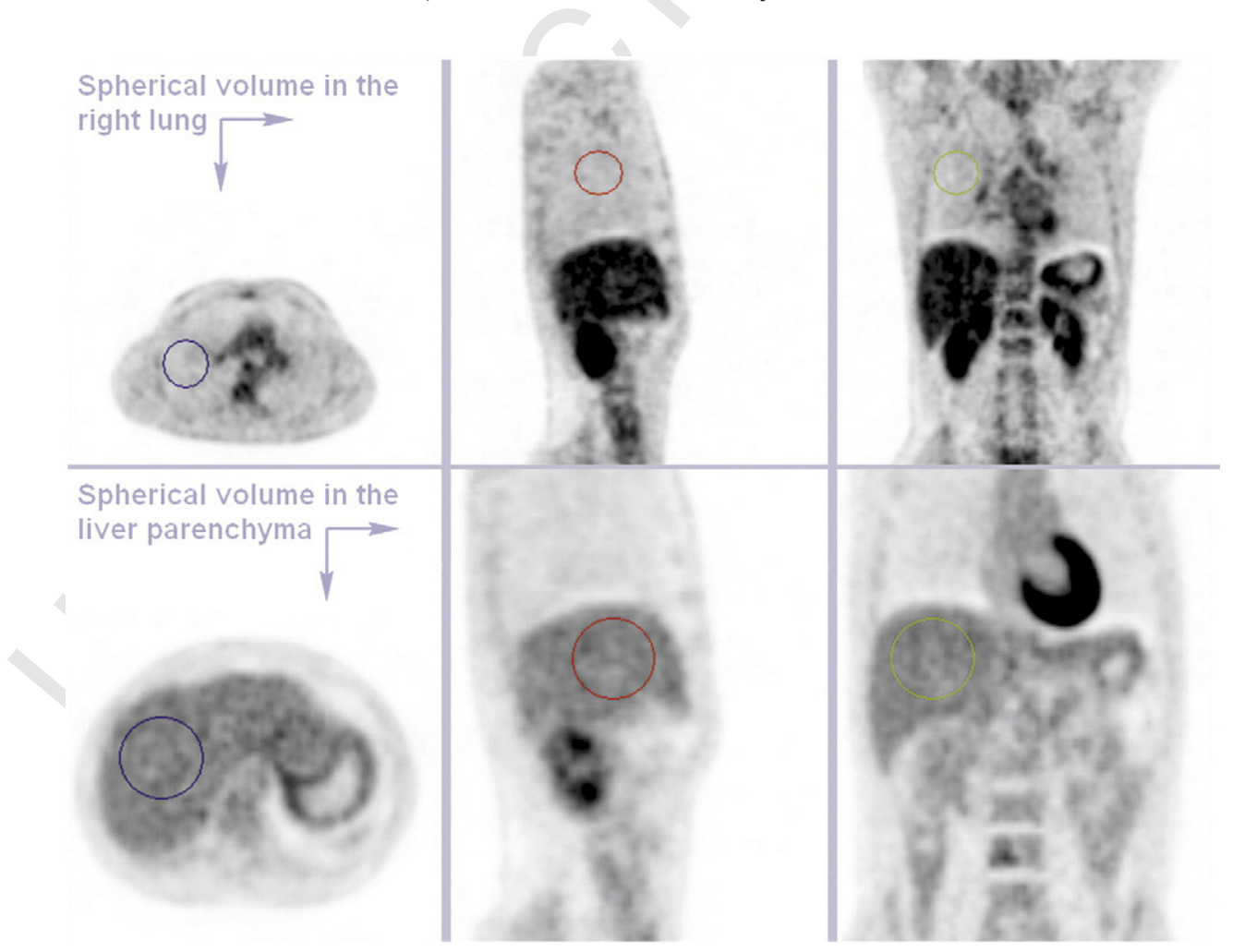

Fig. 2. SUVmax in a spherical volume $(6-8 \mathrm{~cm}$ in diameter) in the right lung was put into relation with SUVmax in a spherical volume (9-10 $\mathrm{cm}$ in diameter) in the reference liver parenchyma to set up the SUVmaxPULMO/SUVmaxHEPAR index. Considering the topographical differences between the lungs and the liver, we were more limited in demarcating the volume of interest in the lung parenchyma, which therefore has smaller diameter. 


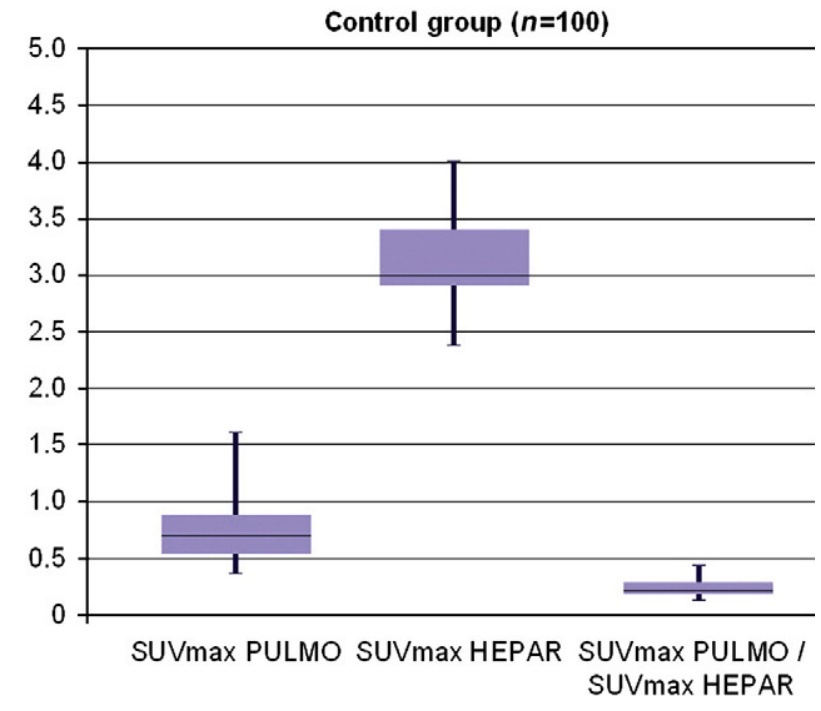

Fig. 3. Box plot of SUV data of control group: median SUVmaxPULMO= 0.70 [range: $0.380-1.600 ; 0.74 \pm 0.26(100)$ ], median SUVmaxHEPAR $=$ 3.00 [range: $2.40-4.00 ; 3.11 \pm 0.35(100)$ ], median SUVmaxPULMO/ SUVmaxHEPAR $=0.22$ [range: $0.14-0.43 ; 0.24 \pm 0.07$ (100)].

larger area. Considering the anatomical conditions, we chose the volume of interest shaped into spheres of $6-8 \mathrm{~cm}$ in diameter in the right lung. The metabolic activity was measured in the right upper and middle lung fields. These are the regions of predominant PLCH involvement. The right side without heart and pericardium is more suitable for demarcating the volume of interest and requires only the exclusion of the hilar structures and pleura, where the activity can be increased physiologically. Moreover, in the lower lung fields, numerous motion artifacts are common. This selection of size and location of the volume of interest strives to maximize the probability of occurrence of the majority of active lesions in the most anatomically suitable region while preserving an easy way of determination in a daily routine.

To decrease the variability between single examinations as well as to compare examinations from different scanners, lung-to-liver activity ratio was assessed. In the liver parenchyma, we chose volume of interest shaped into spheres of $9-10 \mathrm{~cm}$ in diameter following analogous principles as in the lungs (Fig. 2). Consequently, SUVmax in the right lung and SUVmax in the reference hepatic parenchyma were measured, and their relationship expressed 164 as the SUVmaxPULMO/SUVmaxHEPAR index was deter- 165 mined and used for PLCH activity evaluation. 166

In our analysis of a sample of 100 randomly chosen 167 FDG-PET/CT studies free from any known lung or 168 hepatic diseases, either oncological or nononcological, we 169 found index values lower than 0.3 in $80 \%$ and lower than 170 0.4 in $96 \%$ [range: $0.14-0.43 ; 0.24 \pm 0.07$ (100)]. No index 171 values higher than 0.5 were identified in the healthy 172 population. The range of applied activity was 302-425 173 MBq [354.51 \pm 32.12 (100)], and that of blood glucose levels 174 was $3.1-8.1 \mathrm{mmol} / \mathrm{L}[5.00 \pm 1.09$ (100)]. Further SUV data 175 are summarized in Fig. 3.

\section{Results}

177

Six males, all with a history of smoking, and one female, 178 31 to 48 years of age at the time of first FDG-PET scanning 179 $[39.7 \pm 6.5(7)]$, were included in this study. The mean follow- 180 up period was 17 months [range: 9-79 months; 30.4 29.0181 (7)]. Six patients had a multisystemic Langerhans cell 182 histiocytosis with pulmonary involvement and received at 183 least one line of therapy. One patient had isolated PLCH, and 184 this patient has not been treated yet. In patients with 185 multisystemic disease, the following organs were affected: 186 lungs (100\%), skin (65\%), bones (50\%), brain (30\%), ear 187 $(30 \%)$ and lymph nodes (15\%). Respiratory symptoms 188 (dyspnea, cough) were present in five patients (71\%), of 189 whom one patient suffered from recurrent pneumothorax. 190 Demographic and clinical data are shown in Tables 1 and 2. 191

All patients underwent FDG-PET scan imaging (4 PET 192 scans and 23 PET/CT scans). The acquired data, summarized 193 in Table 3, were correlated to the clinical course of the 194 disease, HRCT findings, pulmonary function tests and 195 pathological examinations. In total, 18 HRCT studies 196 $[2.6 \pm 1.3(7)]$ and 13 pulmonary function tests $[1.9 \pm 1.5(7)] 197$ were performed in seven patients. We have found a close 198 correlation between the SUVmaxPULMO/SUVmaxHEPAR 199 index values and the above-mentioned disease activity 200 parameters (Table 2). Consequently, we worked with two 201 variables, the index value and the metabolic tumor activity, 202 and found a relationship with positive slope, i.e., increasing 203 index value corresponds with increasing metabolic tumor 204

Table 1

Main demographic and clinical characteristics of seven patients with PLCH

\begin{tabular}{lllll}
\hline Date of birth, sex & Smoking habitus & $\begin{array}{l}\text { Disease } \\
\text { onset (years) }\end{array}$ & Extrapulmonary involvement & $\begin{array}{l}\text { Diagnosis of pulmonary } \\
\text { involvement (years) }\end{array}$ \\
\hline 1972, M & Smoker & 21 & Bones & 34 \\
1974, M & Smoker & 33 & Skin, brain (pituitary stalk), ear & 34 \\
1969, M & Ex-smoker & 39 & Skin & 40 \\
1963, M & Active and passive smoker & 43 & Ear & 45 \\
1973, M & Smoker & 34 & Skin, bones, lymph nodes & 35 \\
1963, M & Smoker & 45 & Isolated PLCH & 45 \\
1955, F & Nonsmoker & 22 & Skin, bones, brain, ear & 54 \\
\hline
\end{tabular}


Table 2

Correlation between the SUVmaxPULMO/SUVmaxHEPAR index and disease course in seven patients with PLCH

\begin{tabular}{lllll}
\hline $\begin{array}{l}\text { Date of } \\
\text { birth, sex }\end{array}$ & $\begin{array}{l}\text { Date of } \\
\text { PET-CT }^{\text {a }}\end{array}$ & $\begin{array}{l}\text { SUVmax } \\
\text { PULMO/SUVmax } \\
\text { HEPAR }\end{array}$ & $\begin{array}{l}\text { Disease course and symptoms of } \\
\text { pulmonary involvement }\end{array}$ & $\begin{array}{l}\text { Interpretation of SUVmaxPULMO/SUVmaxHEPAR } \\
\text { index in relation to disease course }\end{array}$ \\
\hline 1972, M & Mar 04 & 0.44 & $\begin{array}{l}\text { After 5 cycles of cladribine therapy, remission } \\
\text { of bone lesions } \\
\text { Lasting remission of bone lesions }\end{array}$ & $\begin{array}{l}\text { High index value due to active smoking } \\
\text { Dyspnea, cough } \\
\text { Smoking cessation leading to relief of symptoms }\end{array}$ \\
& Jan 05 & 0.45 & $\begin{array}{l}\text { Progression of PLCH } \\
\text { Gradual remission of PLCH in accordance with } \\
\text { relief of symptoms after cessation of smoking }\end{array}$
\end{tabular}

Screening admission PET/CT

Progression of pituitary stalk infiltration on brain MRI; therapy initiation

Regression of pituitary stalk infiltration

after 3 cycles with cladribine

Disease activity (recurrent pneumothorax, 3 times); therapy initiation

After 6 cycles of cladribine therapy, partial remission of skin lesions

Screening admission PET/CT

After 4 cycles of cladribine therapy

\section{Follow-up PET/CT}

Screening admission PET/CT; dyspnea, cough After 4 cycles with cladribine therapy 1st relapse (confirmed by lymph node and skin biopsies); cough

After 2 cycles of salvage chemotherapy CHOEP; relief of symptoms

4 months after autologous transplantation

2nd relapse (confirmed by lymph node biopsy) Screening admission PET/CT; intermittent cough Stable disease not requiring therapy; lasting intermittent cough

$\begin{array}{lll}\text { 1955, F } & \text { Mar 04 } & 0.42 \\ & \text { Jan 09 } & 0.31 \\ & \text { Mar 10 } & 0.14 \\ \text { May 10 } & 0.17 \\ \text { Oct 10 } & 0.38\end{array}$

Screening admission PET/CT; slight effort dyspnea After several cycles with vinblastine, prednisone and etoposide Progression in brain; therapy initiation After 2 cycles with cladribine Further progression in brain, chemoresistant disease
Increased index value suggests progression in lungs

Therapy effective also in PLCH as suggested by decreasing index value

High index value confirms PLCH

Therapy effective in PLCH as suggested by decreasing index value

High index value confirms PLCH

Gradual remission of PLCH after successful cladribine therapy

High index value confirms PLCH

Therapy effective also in PLCH

Increased index value suggests relapse in lungs

Remission of PLCH after chemotherapy

Lasting remission of PLCH after

autologous transplantation

Increased index value suggests 2 nd relapse in lungs

Slightly increased index value in patient with stable clinical manifestation, but still continuing his smoking habitus

High index value suggests pulmonary involvement Therapy effective also in PLCH

Further remission of PLCH

Lasting remission of PLCH

Increased index suggests progression of PLCH

CHOEP, cyclophosphamide+doxorubicin+vincristine+etoposide+prednisone.
a Between 2004 and 2007, only PET scans were made.

activity and vice versa. The increasing trends of index values were seen in five patients, where they indicated PLCH activity (i.e., pulmonary symptoms, formation of nodules on HRCT or abnormal pulmonary function tests), whereas decreasing trends of index values were observed in six patients after therapy administration, signaling reduced metabolic tumor activity. Furthermore, in four patients, SUVmaxPULMO/SUVmaxHEPAR index values higher than 0.5 proved to be diagnostic for pulmonary involvement, demonstrating its role as a strong positive predictive marker. Fig. 4 shows the disease course with corresponding index values in one patient (male, born 1973).

Quantitative analysis of HRCT findings in patients with PLCH, consisting of assessment of the exact count of nodules and cystic formations, is almost impossible to be 219 obtained. Therefore, the PET-CT findings were correlated to 220 a semiquantitative radiological evaluation of HRCT scans, 221 and neither sensitivity, specificity, accuracy nor predictive 222 values can be exactly calculated in our study.

\section{Discussion}

The clinical course of PLCH is very divergent and 225 impossible to be predicted for an individual patient [2,3]. 226 About $50 \%$ of patients with isolated PLCH have a favorable 227 prognosis with total disease remission, i.e., reduction of 228 pulmonary nodules either spontaneously or after corticoid 229 
Table 3

An overview of PET-CT data in 7 patients with PLCH

\begin{tabular}{|c|c|c|c|c|c|c|}
\hline $\begin{array}{l}\text { Date of } \\
\text { birth, Sex }\end{array}$ & $\begin{array}{l}\text { Date of } \\
\text { PET-CT }^{\text {a }}\end{array}$ & $\begin{array}{l}\text { Applied } \\
\text { activity (MBq) }\end{array}$ & $\begin{array}{l}\text { Blood glucose } \\
\text { levels }(\mathrm{mmol} / \mathrm{L})\end{array}$ & $\begin{array}{l}\text { SUVmax } \\
\text { PULMO }\end{array}$ & $\begin{array}{l}\text { SUVmax } \\
\text { HEPAR }\end{array}$ & $\begin{array}{l}\text { SUVmax } \\
\text { PULMO / SUVmax } \\
\text { HEPAR }\end{array}$ \\
\hline \multirow[t]{6}{*}{ 1972, M } & Mar-04 & 327 & 4.4 & 0.80 & 1.83 & 0.44 \\
\hline & Jan-05 & 321 & 5.8 & 0.81 & 1.79 & 0.45 \\
\hline & Feb-07 & 335 & 4.1 & 1.02 & 2.01 & 0.51 \\
\hline & Jun-08 & 337 & 4.8 & 1.06 & 2.24 & 0.47 \\
\hline & Jan-09 & 315 & 5.2 & 0.92 & 3.22 & 0.29 \\
\hline & Feb-10 & 352 & 4.7 & 0.89 & 3.25 & 0.27 \\
\hline \multirow[t]{3}{*}{ 1974, M } & Mar-09 & 414 & 4.6 & 0.93 & 4.39 & 0.21 \\
\hline & Feb-10 & 431 & 4.8 & 0.89 & 3.25 & 0.27 \\
\hline & Jun-10 & 466 & 5.4 & 0.78 & 3.53 & 0.22 \\
\hline \multirow[t]{2}{*}{ 1969, M } & May-09 & 377 & 4.7 & 1.88 & 3.30 & 0.57 \\
\hline & Mar-10 & 393 & 5.2 & 0.78 & 3.53 & 0.22 \\
\hline \multirow[t]{3}{*}{$1963, \mathrm{M}$} & Mar-09 & 372 & 4.7 & 1.78 & 3.11 & 0.57 \\
\hline & Aug-09 & 421 & 4.9 & 1.79 & 3.36 & 0.53 \\
\hline & Mar-10 & 401 & 4.7 & 1.03 & 2.71 & 0.38 \\
\hline \multirow[t]{6}{*}{ 1973, M } & Jan-09 & 330 & 6.3 & 1.34 & 2.49 & 0.54 \\
\hline & Jun-09 & 336 & 5.6 & 0.68 & 2.23 & 0.31 \\
\hline & Nov-09 & 330 & 5.3 & 1.18 & 3.24 & 0.36 \\
\hline & Jan-10 & 338 & 5.7 & 0.88 & 3,30 & 0.27 \\
\hline & Jul-10 & 317 & 5.5 & 0.75 & 2.72 & 0.28 \\
\hline & Oct-10 & 292 & 6.4 & 1.40 & 2.98 & 0.48 \\
\hline \multirow[t]{2}{*}{ 1963, M } & Jul-08 & 338 & 4.7 & 0.69 & 3.30 & 0.21 \\
\hline & Feb-10 & 354 & 5.1 & 0.95 & 3.96 & 0.24 \\
\hline \multirow[t]{5}{*}{$1955, \mathrm{~F}$} & Mar-04 & 344 & 4.4 & 1.02 & 2.45 & 0.42 \\
\hline & Jan-09 & 337 & 5.8 & 1.00 & 3.19 & 0.31 \\
\hline & Mar-10 & 357 & 6.7 & 0.48 & 3.49 & 0.14 \\
\hline & May-10 & 351 & 5.4 & 0.53 & 3.15 & 0.17 \\
\hline & Oct-10 & 386 & 7.0 & 1.45 & 3.8 & 0.38 \\
\hline
\end{tabular}

${ }^{a}$ Between 2004-2007 only PET scans were made.

therapy. Cessation of smoking proved to be essential in therapy management, leading to remission in many cases described $[6,10,11]$. Nevertheless, cystic lung damage is irreversible. Moreover, PLCH implies a higher risk of lung cancer, especially in smokers, and a higher risk of other malignancies as well [12].

The greatest challenge is the evaluation of PLCH disease activity and, consequently, therapy effectiveness. In recent years, based on a contrasting rate of glucose utilization between rapidly proliferating tumor cells and surrounding normal tissue, much attention has been devoted to the benefit of FDG-PET and FDG-PET/CT scan imaging for determining the extent of Langerhans cell histiocytosis and therapy response evaluation.

Derenzini et al. [13] used FDG-PET for evaluating the effectiveness of MACOP-B chemotherapy in four patients. The FDG-PET scan was able to detect additional lesions missed by other modalities in two patients. A negative interim FDG-PET predicted a long-lasting remission in three of four patients. Phillips et al. [14] published the same experience as they compared the benefit of FDG-PET/CT to bone scans, CT, magnetic resonance imaging (MRI) and conventional radiography for determining the extent of Langerhans cell histiocytosis and evaluation of therapy response in 44 patients ( 41 children and 3 adults). They concluded that whole-body FDG-PET scans can detect 255 disease activity and early response to therapy with greater 256 accuracy than other imaging modalities in patients with 257 Langerhans cell histiocytosis affecting bones and soft 258 tissues. Furthermore, FDG-PET is also beneficial for an 259 early diagnosis of neurodegenerative Langerhans cell 260 histiocytosis [15].

However, a MEDLINE literature search revealed only 262 one paper evaluating FDG-PET scan imaging in PLCH, the 263 work from authors Krajicek et al. [16], who described their 264 cohort study with 11 patients. PET-scan-positive patients 265 had predominantly nodular lung disease with more than 100266 nodules usually under $8 \mathrm{~mm}$ in size, whereas PET-scan- 267 negative patients had predominantly cystic lung disease with 268 nodules numbering less than 25 in a field of examination. $\quad 269$

In our study, all pathology in the lung parenchyma was 270 below detectable levels of the PET scanner (less than $7 \mathrm{~mm}$ ), 271 and we did not find large active lesions. Notwithstanding the 272 observations of Krajicek et al., we describe a new 273 methodology for diffuse metabolic activity evaluation of 274 the lung parenchyma and present the possibility to objectify 275 the results by comparing them with the simultaneously 276 measured activity of the reference liver parenchyma. The 277 evaluation of pulmonary activity based on the index, the ratio 278 of the measured SUVmax value in a spherical volume of the 279 


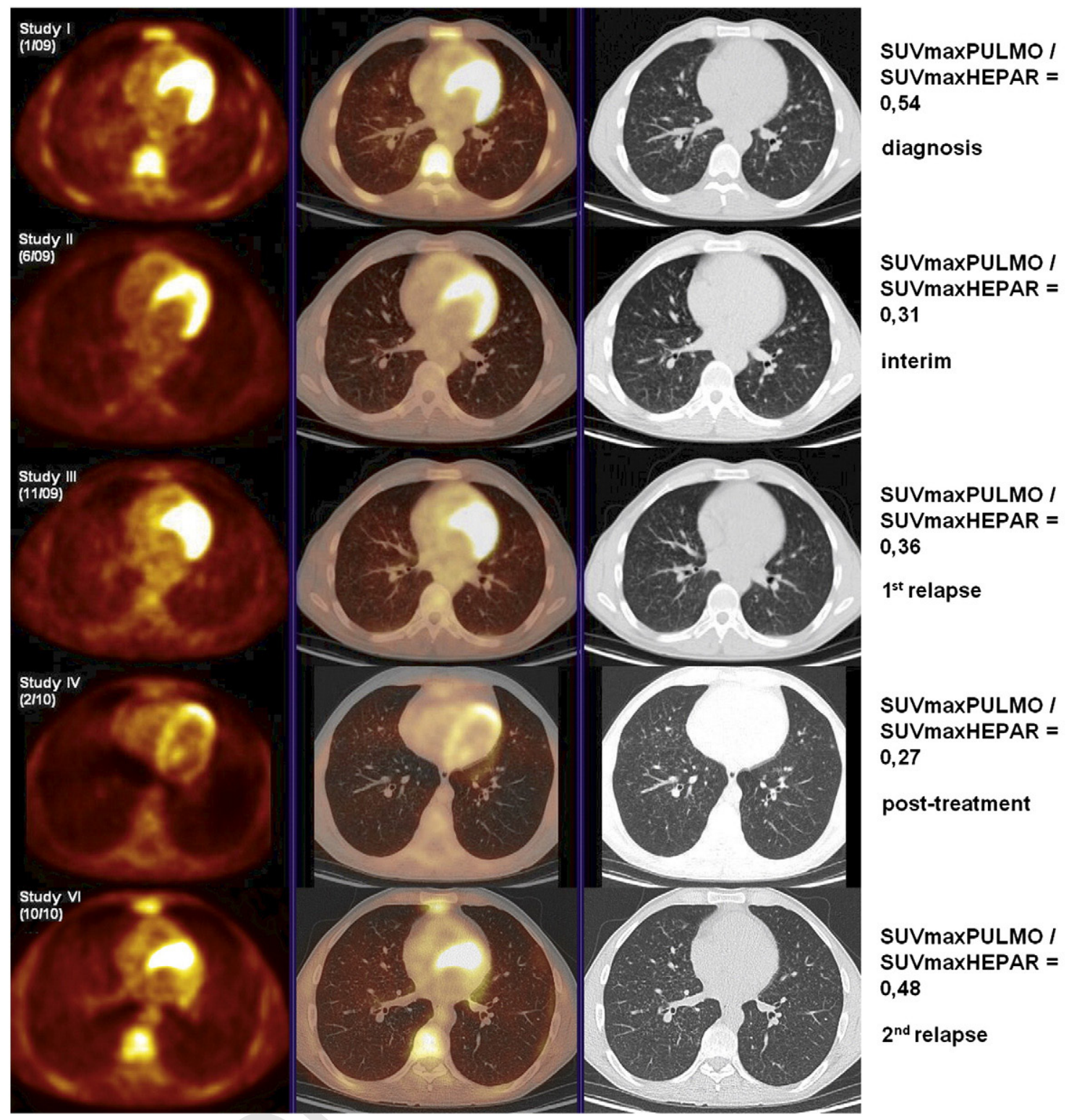

Fig. 4. Series of FDG-PET/CT images of a patient with multisystemic Langerhans cell histiocytosis with pulmonary involvement (male, born 1973). High index value on admission PET/CT together with pathognomonic HRCT finding (multiple small nodules with sporadic cysts) and clinical symptoms (dyspnea, cough) was diagnostic for PLCH. Interim PET/CT after two cycles with cladribine shows a therapy response which correlated with regression of lymphadenopathy and relief of the symptoms, including perianal pruritus and B-symptoms (night sweats, fever and weight loss). However, an aggressive form of Langerhans cell histiocytosis with recurrent relapses was the case. The index value corresponded closely with the disease course. We consider myocardial FDG uptake to be physiological.

right lung to the measured SUVmax value in a spherical volume of the liver - the SUVmaxPULMO/SUVmaxHEPAR index - which we propose and which we have verified, has not been published so far. We are aware of the fact that the method we used is not common and, with such small lesions, it is negatively biased by the partial-volume effect characterized by increasing underestimation of SUV with decreasing lesion sizes [17]. The index may be influenced by concomitant factors affecting either lungs or liver (e.g., other interstitial lung diseases, benign tumors, active infections or noninfectious inflammations, cholestasis, cirrhosis). Moreover, hyperinsulinemia [18], higher glucose level [19] and advanced age [20] were found to be 292 related to increased FDG uptake by liver.

Currently, except for HRCT of the lungs and pulmonary 294 function tests, there is no other modality that informs more 295 accurately on PLCH activity. Traditional FDG-PET scan 296 imaging is not possible due to the small size of nodules 297 which cannot be reliably resolved by the PET scanner. 298 Therefore, we consider the measuring and long-term 299 monitoring of the index SUVmaxPULMO/SUVmaxHEPAR 300 to be very useful additional tools for PLCH activity 301 evaluation. Based on our analysis of a sample of 100302 randomly chosen PET/CT scans, as mentioned above, and on 303 
this retrospective study, we found that SUVmaxPULMO/ SUVmaxHEPAR index values higher than 0.5 bear high probability of pulmonary involvement in patients with Langerhans cell histiocytosis.

In conclusion, measuring the SUVmaxPULMO/SUVmaxHEPAR index and its time-trend monitoring represent simple noninvasive screening tools for PLCH, allowing us to optimize the therapeutic management in the patients. An early diagnosis of pulmonary involvement with a prompt initiation of therapy may prevent progressive cystic damage to the lungs. The index measurement also enables an effective monitoring of therapy response and follow-up of patients with PLCH.

\section{Acknowledgment}

This work was supported in part by the IGA of The Ministry of Health (NT11154, NS10387, FUNDIN MZ0MOU2005); The Ministry of Education, Youth and Sports (LC06027, MSM0021622434); and MUNI/A/1012/2009.

\section{References}

[1] Vassallo R, Ryu JH. Pulmonary Langerhans' cell histiocytosis. Clin Chest Med 2004;25(3):561-71.

[2] Tazi A. Adult pulmonary Langerhans' cell histiocytosis. Eur Respir J 2006;27(6):1272-85.

[3] Sundar KM, Gosselin MV, Chung HL, Cahill BC. Pulmonary Langerhans cell histiocytosis: emerging concepts in pathobiology, radiology, and clinical evolution of disease. Chest 2003;123 (5):1673-83.

[4] Thomeer M, Demedts M, Vandeurzen K, VRGT Working Group on Interstitial Lung Diseases. Registration of interstitial lung diseases by 20 centres of respiratory medicine in Flanders. Acta Clin Belg 2001; 56(3):163-72.

[5] Gaensler EA, Carrington CB. Open biopsy for chronic diffuse infiltrative lung disease: clinical, roentgenographic, and physiological correlations in 502 patients. Ann Thorac Surg 1980;30(5):411-26.

[6] Colby TV, Lombard C. Histiocytosis X in the lung. Hum Pathol 1983; 14(10):847-56.
[7] Watanabe R, Tatsumi K, Hashimoto S, Tamakoshi A, Kuriyama T, 341 Respiratory Failure Research Group of Japan. Clinico-epidemiological 342 features of pulmonary histiocytosis X. Intern Med 2001;40 343 (10):998-1003.

[8] Vassallo R, Ryu JH, Colby TV, Hartman T, Limper AH. Pulmonary 345 Langerhans'-cell histiocytosis. N Engl J Med 2000;342(26): 346 1969-78.

347

[9] Schönfeld N, Frank W, Wenig S, Uhrmeister P, Allica E, Preussler H, 348 et al. Clinical and radiologic features, lung function and therapeutic 349 results in pulmonary histiocytosis X. Respiration 1993;60(1):38-44. 350

[10] Mogulkoc N, Veral A, Bishop PW, Bayindir U, Pickering CA, Egan JJ. 351 Pulmonary Langerhans' cell histiocytosis: radiologic resolution 352 following smoking cessation. Chest 1999;115(5):1452-5. 353

[11] Friedman PJ, Liebow AA, Sokoloff J. Eosinophilic granuloma of 354 lung. Clinical aspects of primary histiocytosis in the adult. Medicine 355 (Baltimore) 1981;60(6):385-96.

[12] Tomashefski JF, Khiyami A, Kleinerman J. Neoplasms associated 357 with pulmonary eosinophilic granuloma. Arch Pathol Lab Med 1991;115 358 (5):499-506.

[13] Derenzini E, Fina MP, Stefoni V, Pellegrini C, Venturini F, Broccoli 360 A, et al. MACOP-B regimen in the treatment of adult Langerhans cell 361 histiocytosis: experience on seven patients. Ann Oncol 2010;21 362 (6):1173-8.

[14] Phillips M, Allen C, Gerson P, McClain K. Comparison of FDG-PET 364 scans to conventional radiography and bone scans in management of 365 Langerhans cell histiocytosis. Pediatr Blood Cancer 2009;52 366 (1):97-101.

[15] Ribeiro MJ, Idbaih A, Thomas C, Remy P, Martin-Duverneuil N, 368 Samson Y, et al. 18F-FDG PET in neurodegenerative Langerhans cell 369 histiocytosis : results and potential interest for an early diagnosis of the 370 disease. J Neurol 2008;255(4):575-80.

[16] Krajicek BJ, Ryu JH, Hartman TE, Lowe VJ, Vassallo R. Abnormal 372 fluorodeoxyglucose PET in pulmonary Langerhans cell histiocytosis. 373 Chest 2009;135(6):1542-9.

[17] Hoetjes NJ, van Velden FH, Hoekstra OS, Hoekstra CJ, Krak NC, 375 Lammertsma AA, et al. Partial volume correction strategies for 376 quantitative FDG PET in oncology. Eur J Nucl Med Mol Imaging 377 2010;37(9):1679-87.

[18] Iozzo P, Geisler F, Oikonen V, Mäki M, Takala T, Solin O, et al. 18F- 379 FDG PET Study. Insulin stimulates liver glucose uptake in humans: an 380 18F-FDG PET Study. J Nucl Med 2003;44(5):682-9.

[19] Kubota K, Watanabe H, Murata Y, Yukihiro M, Ito K, Morooka M, 382 et al. Effects of blood glucose level on FDG uptake by liver: a FDG- 383 PET/CT study. Nucl Med Biol 2011;38(3):347-51.

[20] Lin CY, Ding HJ, Lin CC, Chen CC, Sun SS, Kao CH. Impact of 385 age on FDG uptake in the liver on PET scan. Clin Imaging 2010; 386 34(5):348-50. 


\section{AUTHOR QUERY FORM}

\begin{tabular}{|c|c|c|}
\hline 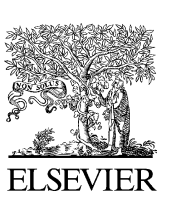 & $\begin{array}{l}\text { Journal: NMB } \\
\text { Article Number: } 7094\end{array}$ & $\begin{array}{l}\text { Please e-mail or fax your responses and any corrections to: } \\
\text { Shayna Bayard } \\
\text { E-mail: sbayard@verizon.net } \\
\text { Tel: } 215-844-8326 \\
\text { Fax: } 215-844-4292\end{array}$ \\
\hline
\end{tabular}

Dear Author,

Please check your proof carefully and mark all corrections at the appropriate place in the proof (e.g., by using on-screen annotation in the PDF file) or compile them in a separate list. Note: if you opt to annotate the file with software other than Adobe Reader then please also highlight the appropriate place in the PDF file. To ensure fast publication of your paper please return your corrections within 48 hours.

For correction or revision of any artwork, please consult http://www.elsevier.com/artworkinstructions.

Any queries or remarks that have arisen during the processing of your manuscript are listed below and highlighted by flags in the proof. Click on the 'Q' link to go to the location in the proof.

\begin{tabular}{|l|l|}
\hline $\begin{array}{c}\text { Location } \\
\text { in article }\end{array}$ & \multicolumn{1}{c|}{$\begin{array}{c}\text { Query / Remark: click on the Q link to go } \\
\text { Please insert your reply or correction at the corresponding line in the proof }\end{array}$} \\
\hline Q1 & Please confirm that given names and surnames have been identified correctly. \\
\hline Q2 & Please spell out if an abbreviation/acronym. \\
\hline
\end{tabular}

Thank you for your assistance. 